\title{
Studi Meta-Analisis: Hubungan Antara Beban Kerja dengan Stres Kerja
}

\section{Meta-Analysis Study: A Correlation Between workload and work stress}

\author{
Ikhbal Hidayat Lubis* \\ Program Studi Psikologi Islam, Sekolah Tinggi Agama Islam Aceh Tamiang, Indonesia \\ Disubmit: 26 April 2021; Diproses: 27 April 2021; Diaccept: 01 Agustus 2021; Dipublish: 02 Agustus 2021 \\ *Corresponding author: E-mail: cubulbul@gmail.com
}

\begin{abstract}
Abstrak
Stres kerja stres kerja adalah perasaan ataupun kondisi emosional karyawan juga kondisi psikis yang sedang dialami oleh karyawan ketika merasa lelah, jenuh, bosan dan capek. Telah banyak penelitian yang dilakukan oleh peneliti terdahulu tentang stres kerja karyawan dan salah satunya adalah beban kerja karyawan yang memiliki keterkaitan pada tinggi dan rendahnya stres kerja seseorang karyawan. Pada penelitian ini dilakukan dengan menggunakan teknik studi meta-analisis dan bertujuan untuk meneliti hubungan antara beban kerja dan stres kerja karyawan. Penelitian ini melakukan reviu yang melibatkan 7 studi jurnal yang berkaitan dengan motivasi kerja dan kinerja karyawan pada 10 tahun terakhir dan dengan jumlah responden sebanyak 448. Hasil dari penelitian studi meta-analisis ini menunjukkan korelasi yang small effect size sebesar $\mathrm{r}=0,57(95 \% \mathrm{CI}=0.361,0.72)$ confidance intervalnya akan ada heterogeneity $I^{2}=85.2 \%$ maka meta-analisis ini menggunakan random effect size. Dari hasil tersebut mengindikasikan bahwa motivasi kerja kurang berkorelasi dengan kinerja karyawan secara langsung dikarenakan memiliki medium effect size . hal ini mengisyaratkan ada variabel beban kerja memberikan pengaruh ataupun efek yang cukup sedang terhadap stres kerja karyawan.
\end{abstract}

Kata Kunci: Stres Kerja; Karyawan; Beban kerja; Meta-Analisis.

\begin{abstract}
Work stress is a feeling or emotional condition of employees as well as psychological conditions that are being experienced by employees when they feel tired, bored, bored and tired. There have been many studies conducted by previous researchers about employee work stress and one of them is the workload of employees which has a relationship with the high and low work stress of an employee. This research was conducted using a meta-analysis study technique and aimed to examine the relationship between workload and employee work stress. This study conducted a review involving 7 journal studies related to work motivation and employee performance in the last 10 years and with a total of 448 respondents. The results of this meta-analysis study showed a small effect size correlation of $r=0.57$ (95 \%CI=0.361.0.72) the confidence interval will have heterogeneity ${ }^{2}=85.2 \%$, so this meta-analysis uses a random effect size. These results indicate that work motivation is not directly correlated with employee performance because it has a medium effect size. This implies that there is a workload variable that has a moderate or moderate effect on employee work stress.
\end{abstract}

Keywords: Job Stress; Employee; Workload; Meta-Analysis.

DOI: https://doi.org/10.51849/j-p3k.v2i2.105

Rekomendasi mensitasi :

Lubis, I.H. (2021), Studi Meta-Analisis: Hubungan Antara Beban Kerja dengan Stres Kerja. Jurnal Penelitian Pendidikan, Psikologi dan Kesehatan (J-P3K), 2 (2): 188193. 


\section{PENDAHULUAN}

Beratnya tuntutan pekerjaan seorang karyawan menyebabkan para karyawan mengalami rasa jenuh, bosan, suntuk dan yang pada akhirnya dapat menyebabkan karyawan tersebut merasa jenuh dalam menjalani pekerjaan didalam perusahaan. Rasa jenuh, bosan dan suntuk karyawan akan sangat mempengaruhi kinerja karyawan. Rasa terbeban karyawan akan pekerjaan akan dapat membuat karyawan tersebut menjadi stres kerja. Sehingga mempengaruhi produktifitasnya pada perusahaan tempat karyawan tersebut bekerja.

Beban kerja menurut Hart \& Stavelan dalam (Manabung et al., 2019) adalah merupakan sesuatu yang muncul dari interaksi antara tuntutan tugas-tugas, lingkungan kerja dimana digunakan sebagai tempat kerja, keterampilan, perilaku dan persepsi dari pekerja.

Beban kerja yang tidak sesuai pada kapasitas kinerja karyawan akan dapat menyebabkan ketidaknyamanan seorang karyawan, karena harus memaksakan keadaan dirinya untuk dapat bekerja sesuai dengan tuntutan yang diberikan oleh perusahaan, bila kemampuannya tidak sebanding dengan kualitas fisik maupun keahlian khusus serta waktu yang tersedia maka akan menjadi sumber stres (Ilyas, 2002).

Tingginya tekanan yang diberikan oleh perusahaan dapat menyebabkan karyawan yang tidak sesuai pada kemampuannya akan membuat dirinya merasa terbebani akan beban pekerjaan yang diberikan oleh perusahaan. Semakin terbebani nya karyawan dapat menyebabkan karyawan tersebut akan menjadi stres, hal ini didukung oleh Schultz (1982) dirinya menjelaskan bahwa aspek- aspek yang dapat menimbulkan stres kerja adalah beban kerja yang berlebihan, baik secara kualitatif maupun kuantitatif.

Menurut Mangkunegara (2011) stres kerja adalah perasaan yang dialami oleh karyawan dalam menghadapi pekerjaan. Stres kerja adalah suatu kondisi terganggunya keseimbangan fisik dan psikis, yang dapat mempengaruhi emosi, proses berpikir dan kondisi seorang karyawan dan menurut Rivai (2004) muncul berbagai gejala stres yang dapat menganggu pelaksanaan kerja mereka.

Menurut Cox (2000) stres kerja ia identifikasi bahwa ada lima sumber stres kerja diantaranya yaitu ; beban kerja, kesulitan berhubungan dengan staf lain, kesulitan menjadi perawat di unit perawatan kritis, ketentuan pengobatan pasien, dan kesulitan menghadapi pasien yang tidak ada harapan.

Begitu banyak faktor yang mempengaruhi stres kerja karyawan kemudian pada penelitian ini hanya menggunakan salah satu faktor saja yaitu ; beban kerja. Berdasarkan penelitian yang telah dilakukan oleh peneliti peneliti sebelumnya menunjukkan bahwa beban kerja seseorang dapat mempengaruhi tinggi rendah nya stres karyawan, seperti pada penelitian yang dilakukan oleh Kusnadi (2014) mengungkapkan bahwa terdapat hubungan yang positif antara beban kerja dengan stres kerja dengan nilai korelasi 0,782 .

Penelitian yang dilakukan oleh kusnadi juga didukung oleh penelitian yang dilakukan oleh Sari \& Rayni (2020) pada penelitiannya mengungkapkan bahwa terdapat hubungan yang bermakna antara beban kerja dengan stres kerja dengan nilai korelasi 0,534. Hal ini menunjukkan bahwa beban kerja memang 
mempengaruhi stres kerja seseorang secara nyata.

Berdasarkan pemaparan diatas oleh peneliti didapatkan bahwa terdapat hubungan yang positif antara beban kerja dengan stres kerja namun pada penelitian ini peneliti bermaksud untuk melihat lebih mendalam dengan mengkaji hubungan antara beban kerja dengan stres kerja pada karyawan dengan menggunakan pendekatan penelitian meta analisis

\section{METODE PENELITIAN}

Pada penelitian ini, peneliti melakukan penelusuran terhadap penelitian yang telah dilakukan sebelumnya yang berhubungan dengan hubungan antara beban kerja dengan stres kerja pada karyawan dengan kata kunci; hubungan antara beban kerja dengan stres kerja pada karyawan. Pada penelitian ini data yang didapatkan diperoleh dari Google Scholar dan Researchgate.

Dari hasil penelusuran yang dilakukan oleh peneliti, peneliti menemukan 7 jurnal yang telah dipublikasi dengan berbahasa Indonesia yang berkaitan dengan hubungan antara motivasi kerja dengan kinerja karyawan, dan memuat adanya total responden $(\mathrm{N})$ serta adanya hasil dari korelasinya (r). Metode yang digunakan pada penelitian ini adalah meta-analisis. Meta-Analisis merupakan penelitian yang menggunakan penelitian yang telah ada dan telah dgunakan oleh penelitian lalu dianalisis kembali secara sistematis dan kuantitatif untuk memperoleh sebuah hasil kesimpulan. Meta-Analisis menurut Card, 2012 (Utami \& Helmi, 2017) adalah suatu bentuk penelitian dari beberapa penelitian yang sudah dilakukan dan berfokus pada hasil yang telah ditemukan didalam penelitian-penelitian tersebut.

Pada penelitian ini peneliti menganalisis data dengan menggunakan website Meta-mar (free Online MetaAnalysis Service) dan menggunakan pedoman PRISMA (Preferred Reposrting Items for Systematic Review and Meta Analysis) Serta MARS (MetaAnalysis Reporting Standards). Kemudian kriteria dari jurnal yang akan digunakan pada penelitian ini yaitu jurnal dalam 10 tahun terakhir yang menggunakan metode kuantitatif korelasi. Berikut gambar 1 skema proses pencarian jurnal pada penelitian:

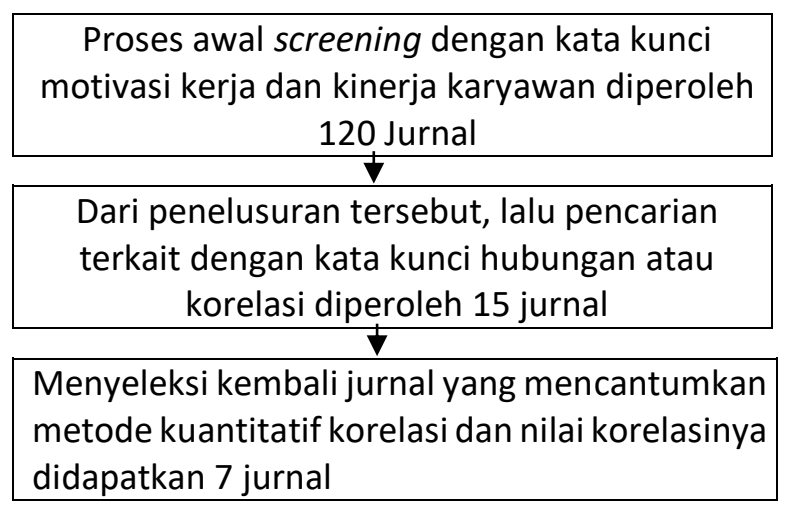

Gambar 1. Foresplot-Fixed dan Random Effect Models

\section{HASIL DAN PEMBAHASAN}

Dari hasil proses penelusuran yang dilakukan oleh peneliti maka diperoleh jurnal sebanyak 120 jurnal terkait beban kerja dan stress kerja pada karyawan. Kemudian peneliti memfokuskan penelusurannya pada jurnal hubungan atau korelasi beban kerja dan stres kerja pada karyawan sehingga diperoleh sebanyak 15 jurnal. Lalu peneliti pun menseleksi kembali hingga didapatkan 7 jurnal yang kemudian dipakai dalam penelitian. 
Penelitian ini dilakukan dengan bervariasi dari 19 hingga 161. Hasil menggunakan 7 jurnal dengan jumlah penelusuran koefisien korelasi, jumlah responden sebanyak 448. Jurnal yang sampel serta data jurnal yang sudah digunakan oleh peneliti diperoleh dari digunakan dapat dilihat pada tabel negara Indonesia saja, jumlah sampel dibawah ini:

Tabel 1. Hasil Penelusuran Data Penelitian

\begin{tabular}{|c|c|c|c|}
\hline Peneliti dan Tahun & Judul Penelitian & Sample Size & Korelasi \\
\hline Miqdad Arats Kusnadi, (2014) & $\begin{array}{l}\text { Hubungan Antara Beban Kerja } \\
\text { dan Self-Efficacy Dengan Stres } \\
\text { Kerja Pada Dosen Universitas X }\end{array}$ & 161 & 0,782 \\
\hline Ike Prafita Sari, Rayni, (2020) & $\begin{array}{l}\text { Hubungan Beban kerja dengan } \\
\text { Stres Kerja Perawat Di RSI } \\
\text { Nashrul Ummah Lamongan }\end{array}$ & 19 & 0,534 \\
\hline $\begin{array}{l}\text { Putri B. Mohune, Budi Ratag, } \\
\text { Woodford B. S. Joseph (2018) }\end{array}$ & $\begin{array}{l}\text { Hubungan Antara Beban Kerja } \\
\text { dengan Stres Kerja pada Pekerja } \\
\text { Unit Airport Rescue And Fire } \\
\text { Fighting di Bandar Udara } \\
\text { International SAMRATULANGI } \\
\text { Manado }\end{array}$ & 53 & 0,647 \\
\hline Hety Umriyani Safitri (2020) & $\begin{array}{l}\text { Hubungan Beban Kerja dengan } \\
\text { Stres Kerja }\end{array}$ & 84 & 0.444 \\
\hline $\begin{array}{l}\text { Zulkifli1, Shinta Tri R2, Sulung } \\
\text { Alfianto Akbar (2019) }\end{array}$ & $\begin{array}{l}\text { Hubungan Usia, Masa Kerja dan } \\
\text { Beban Kerja dengan Stres Kerja } \\
\text { Pada Karyawan Service Well } \\
\text { Company PT. Elnusa TBK } \\
\text { Wilayah Muara Badak }\end{array}$ & 40 & 0,300 \\
\hline $\begin{array}{l}\text { Haryanti, Faridah Aini, } \quad \text { Puji } \\
\text { Purwaningsih (2013) }\end{array}$ & $\begin{array}{l}\text { Hubungan Antara Beban Kerja } \\
\text { dengan Stres Kerja Perawat di } \\
\text { Instalasi Gawat Darurat RSUD } \\
\text { Kabupaten Semarang }\end{array}$ & 29 & 0,751 \\
\hline $\begin{array}{l}\text { Apriliani R Manabung, Lery F. } \\
\text { Suoth, Finny Warouw (2018) }\end{array}$ & $\begin{array}{l}\text { Hubungan Antara Masa Kerja } \\
\text { dan Beban Kerja dengan Stres } \\
\text { Kerja Pada Tenaga Kerja di PT. } \\
\text { Pertamina TBBM Bitung }\end{array}$ & 62 & 0,293 \\
\hline
\end{tabular}

Pengujian data meta-analisis ini dilakukan dengan menggunakan website Meta-mar (Free Online Meta-Analysis Service) kemudian peneliti menginput judul penelitian jumlah subjek yang digunakan dan hasil dari korelasi dari tiap tiap penelitian.

Selanjutnya hasil outputnya memuat beberapa hal yaitu Inconsistency (I2), Hedges-olkin random atau fixed effects dan Foresplot. Untuk mengetahui bagian yang menunjukkan hasil besaran efek yakni dengan melihat hasil hedges-olkin random atau fixed effects.

Kemudian untuk menentukan antara random atau fixed dengan melihat berapa besar persentase inkonsistensi (I2). Apabila hasil inkonsistensi memiliki persentase kurang dari sama dengan $80 \%$ maka fixed effects yang digunakan. 
Akan tetapi, apabila nilai persentasenya lebih dari $80 \%$ maka random effects yang digunakan. Untuk korelasi meta-analisis perhitungannya apabila nilai effects size berada dibawah 0,1 dan berada sampai rentang 0,3 maka memiliki small effects size. Sementara apabila nilai effects size berada pada rentang 0,3 sampai 0,5 maka memiliki medium effects size. Kemudian jika nilai effects size lebih dari 0,5 maka memiliki large effects size.

Berdasarkan data diatas dari 7 jurnal yang telah di analisis dan telah dihitung maka studi korelasi pada penelitian ini menunjukkan bahwa terdapat hubungan positif antara variabel beban kerja dengan stres kerja karyawan. Hasil statistik menunjukkan inkonsistensi sebesar 85,2\% $>$ 80\%, maka random effects size dipilih. Lalu nilai random effects size yaitu sebesar $0,57 \quad(95 \% \mathrm{CI}=0.361,0.72)$ yang berarti terdapat medium effects size antara beban kerja terhadap stres kerja seseorang karyawan. Berikut merupakan tabel lampiran hasil dari meta-analisis dan hasil random effect models menggunakan website Meta-mar (Free Online MetaAnalysis Service).

Tabel 2. Hasil Fixed dan Random Effects Models

\begin{tabular}{|c|c|c|c|c|c|c|c|}
\hline & $\begin{array}{l}\text { Fish } \\
\text { er Z }\end{array}$ & $\mathrm{r}$ & SE & $\begin{array}{l}95 \% \\
\text { CI }\end{array}$ & $\begin{array}{l}z \\
\text { sor } \\
\text { e }\end{array}$ & $\begin{array}{l}\mathrm{p} \\
\text { value }\end{array}$ & $\begin{array}{l}\text { Heterogen } \\
\text { eity }\end{array}$ \\
\hline $\begin{array}{l}\text { Fixed } \\
\text { Effect } \\
\text { Model }\end{array}$ & 0.72 & $\begin{array}{l}0.6 \\
2\end{array}$ & $\begin{array}{l}0.04 \\
8\end{array}$ & $\begin{array}{l}0.55 \\
4,0.67 \\
2]\end{array}$ & $\begin{array}{l}14.8 \\
71\end{array}$ & 0.0 & $\begin{array}{l}\mathrm{I}^{2}=85.2 \% \\
\mathrm{Chi}^{2}=40.65 \\
\mathrm{df}=6\end{array}$ \\
\hline $\begin{array}{l}\text { Rando } \\
\mathrm{m} \\
\text { Effect } \\
\text { Model }\end{array}$ & 0.64 & $\begin{array}{l}0.5 \\
7\end{array}$ & $\begin{array}{l}0.13 \\
5\end{array}$ & $\begin{array}{l}{[0.36} \\
1,0.72 \\
]\end{array}$ & $\begin{array}{l}4.75 \\
4\end{array}$ & 0.0 & $\begin{array}{l}\mathrm{I}^{2}=85.2 \% \\
\mathrm{Tau}^{2}=0.104\end{array}$ \\
\hline
\end{tabular}

Berdasarkan perhitungan uji statistika meta-analisis diatas antara motivasi kerja dan kinerja karyawan diperoleh hasil medium effect size $(0,57)$ maka dapat diartikan beban kerja memberikan efek yang cukup sedang pada stres kerja karyawan. Hasilnya yang cukup sedang dan sedangnya efek tersebut dapat disebabkan oleh memang beban kerja ini cukup memberikan pengaruh seseorang karyawan akan stres kerjanya

Meskipun menurut Cox (2000) stres kerja ia identifikasi ada lima sumber stres kerja diantaranya yaitu ; beban kerja, kesulitan berhubungan dengan staf lain, kesulitan menjadi perawat di unit perawatan kritis, ketentuan pengobatan pasien, dan kesulitan menghadapi pasien yang tidak ada harapan. Namun nyatanya berdasarkan hasil reviu dari 7 artikel penelitian yang sejenis membuktikan bahwa beban kerja cukup memberikan efek pengaruh kepada stres kerja.

Hal ini sejalan dengan penelitian yang telah dilakukan oleh safitri (2020) bahwa terdapat hubungan yang positif antara beban kerja dengan stres kerja dengan nilai korelasi sebesar 0.444, hal ini membuktikan juga bahwa beban kerja secara nyata mempengaruhi stress kerja seseorang

Begitu juga penelitian yang dilakukan oleh Kusnadi (2014) dari hasil penelitian yang ia lakukan didapatkan bahwa korelasi antara beban kerja dengan stres kerja dengan nilai sebesar 0,782 , dengan total responden sebanyak 161, hal ini sudah mendukung dari hasil penelitian meta analisis ini, bahwa terdapat efek yang cukup mempengaruhi yang diberikan oleh beban kerja akan stres kerja pada karyawan.

Meskipun ada faktor faktor lain yang mempengaruhi stres kerja, namun nyatanya setelah dilakukan penelitian meta analisis ini didapatkan hasil bahwa beban kerja ini cukup memberikan efek yang cukup, dibandingkan dengan faktor faktor lain yang mempengaruhi stres kerja pada karyawan. 
Maka dengan demikian pada penelitian meta-analisis antara beban kerja dengan stres kerja pada karyawan memberikan efek yang cukup sedang disebabkan oleh adanya faktor-faktor variabel yang lainnya dalam memberikan pengaruh pada stres kerja karyawan sendiri dari ada variabel beban kerja.

\section{SIMPULAN}

Kesimpulan pada penelitian ini menunjukkan bahwa beban kerja memiliki efek medium to large effects dalam mempengaruhi kinerja karyawan. Dimana beban kerja memberikan efek yang sedang atau bisa disebut cukup signifikan terhadap stres kerja karyawan.

Saran untuk penelitian selanjutnya pada penelitian studi meta-analisis adalah penulis dapat mengkategorikan responden penelitian dikarenakan setiap responden memiliki dinamika motivasi kerja yang berbeda beda.

\section{DAFTAR PUSTAKA}

Cox, T., \& Griffith, A. (200o). Work Related Stress in Nursing: Controlling the Risk to Health: International Labour Office Geneva.

Ilyas, Y. (2002). Perencanaan Sumber Daya manusia Rumah Sakit. UGM.

Kusnadi, M. A. (2014). Hubungan antara beban kerja dan self-efficacy dengan stres kerja pada dosen Universitas X. Calyptra: Jurnal Ilmiah Mahasiswa Universitas Surabaya, 3(1), 1-15. file://C:/Users/User/Downloads/1751Article Text-3217-1-10-20190219 (1).pdf

Manabung, A. R., Suoth, L. F., \& Warouw, F. (2019). Hubungan Antara Masa Kerja Dan Beban Kerja Dengan Stres Kerja Pada Tenaga Kerja Di Pt. Pertamina Tbbm Bitung. Kesmas, 7(5).

Mangkunegara. (2011). Manajemen Sumber Daya Perusahaan (R. Rosdakarya (ed.)).

Prafita ike, S., \& Rayni. (2020). Hubungan Beban Kerja Dengan Stres Kerja Perawat Di Rsi
Nashrul Ummah Lamongan. In Hospital Majapahit (Vol. 12, Issue 1, pp. 9-17).

Safitri, H. U. (2020). Hubungan beban kerja dengan stres kerja. Psikoborneo, 8(2), 174179 .

Schultz, D. . (1982). Psychology and Industry today : An Introduction to Industrial and Organizational Psychology. Mc Millan inc.

Veithzal, R. (2004). Manajemen Sumber Daya Manusia Untuk Perusahaan. Dari Teori Ke Praktik. PT. Raja Grafindo Persada. 